\title{
Anatomical variations of the phrenic nerve: an actualized review
}

\author{
PRATES JÚNIOR, A. G. * , VASQUES, L. C. and BORDONI, L. S. \\ Department of Propaedeutics and Surgery, Medical School, Universidade Federal de Ouro Preto - UFOP, Campus \\ Morro do Cruzeiro, CEP 35400-000, Ouro Preto, MG, Brazil \\ *E-mail: antonio.ufop@gmail.com
}

\begin{abstract}
Introduction: The phrenic nerve normally arises from ventral rami of C3, C4 and C5. It emerges laterally to the superior portion of lateral border of scalenus anterior muscle and presents a descendent course between subclavian artery and vein. It crosses anterior to internal thoracic artery and descends through the mediastinum, until the diaphragm muscle, to supply it with motor and sensitive fibers. Matherials and Methods: A bibliographic review was conducted, based on anatomy, neuroanatomy and surgical anatomy textbooks, published in Brazil and abroad, as well as a review of scientific articles, published over the last 20 years, available on research databases PubMed, Scielo, LILACS and MEDLINE, from keywords phrenic nerve, variation and anomaly. Results: Variations of the phrenic nerve are frequent, but they are not often discussed. Thus, we aimed to conduct an actualized review over the subject. Regarding the variations in the origin of the phrenic nerve, textbooks vaguely inform that it is mainly formed by C4, but the recent cadaveric studies pointed the segments C4 and C5 as the most common origin. About the variations in its course, the most described is its passage anterior to the subclavian vein, before reaching the thorax. However, the presence of accessory phrenic nerve represents the greatestvariation, mostly arising from nerve to subclavian. There are few reports in literature about the complications associated to these variations, but some are suggested, as the possibility of causing its damage during the puncture of the subclavian vein, when the nerve descends anterior to it, which may lead to a hemidiaphragmatic paresis. When variations are present, even simple procedures may cause injuries. Conclusion: Therefore it is fundamental to know the normal anatomy and the possible variations of the phrenic nerve, in order to perform safe procedures in its topography, as well as to enable a timely recognition of complications.
\end{abstract}

Keywords: phrenic nerve, anatomic variation, surgery.

\section{Introduction}

The phrenic nerve $(\mathrm{PN})$ is a mixed spinal nerve, normally arising from the ventral rami of medullary segments $\mathrm{C} 3$, C4 and C5. It is the only responsible for the motor supply of the diaphragm muscle, but it also supplies, with sensory fibers, the central portion of the diaphragm, the mediastinal parietal pleura, the fibrous pericardium and the parietal serous pericardium. Within cervical region, it arises laterally to the superior portion of lateral border of scalenus anterior muscle, and then presents an anterior descendent course, undercovered by prevertebral fascia. It reaches the thorax, normally, anterior to the subclavian artery and posterior to the subclavian vein (Figure 1). In thorax, it initially presents an inferomedial course, crossing anterior to the internal thoracic artery, passing then, in mediastinum, between the fibrous pericardiaum and the mediastinal pleura, along with pericardiophrenic vessels, anterior to the pulmonary hilum, until the diaphragm muscle. The nerve is distributed over this muscle and sends to its inferior side phrenic abdominal branches (MOORE, DALLEY and AGUR, 2011; STANDRING, 2004).

The right and left phrenic nerves are related to different structures at the root of the neck and in mediastinum, once these regions are not symmetric. Thus, the right phrenic nerve reaches the thorax passing anterior to the second portion of the right subclavian artery - portion of the artery that is posterior to scalenus anterior muscle. In the thorax, this nerve is related to the right brachiocephalic vein and to superior cava vein, and then continues inferiorly, separated by the pericardium, from the right atrium and inferior cava vein. The left phrenic nerve passes posterior to the thoracic duct and anterior to the first portion of the left subclavian artery - portion of the artery medial to the scalenus anterior muscle, and in thorax, it is related to left brachiocephalic vein and left ventriculum (STANDRING, 2004; PETROIANU, 1999).

Anatomic variations of the $\mathrm{PN}$ have already been described in the past (ANSON and MCVAY, 1971; BERGMAN, THOMPSON, AFIFI et al., 1988), but the anatomy textbooks (STANDRING, 2004; MOORE, DALLEY and AGUR, 2011) are succinct in relation to this topic. Some of these variations are very often and may have surgical implications, even in simple and widely performed procedures. The present study aims to conduct an updated review over these variations and its possible repercussions.

\section{Materials and Methods}

A bibliographic review was conducted, based on anatomy, neuroanatomy and surgical anatomy textbooks, published in Brazil (MOORE, DALLEY and AGUR, 2011; PETROIANU, 1999; MACHADO, 1998) and abroad (STANDRING, 2004; ANSON and MCVAY, 1971; SKANDALAKIS, COLBORN, WEIDMAN et al., 2004), as well as a review of scientific articles, published over the last 20 years, available on research databases PubMed, Scielo, LILACS and MEDLINE, from keywords phrenic nerve, variation and anomaly. After a critical reading 
of the title and/or the abstract, we selected English articles that reported variations on the phrenic nerve or its secondary consequences. From the initial search, were consulted the references of the previously selected articles, choosing the relevant ones by the same criteria of eligibility.

\section{Results}

The anatomical variations reported on literature can be classified as: variations in the nerve roots that give rise to the $\mathrm{PN}$; variations in its course; and presence of accessory phrenic nerve $(\mathrm{APN})$. These variations can happen associated or not.

Origin of the phrenic nerve

The anatomy textbooks (MOORE, DALLEY and AGUR, 2011 ; SKANDALAKIS, COLBORN, WEIDMAN et al., 2004; STANDRING, 2004; PETROIANU, 1999; MACHADO, 1998 ) vaguely inform that the phrenic nerve is mainly formed by $\mathrm{C} 4$, with contribution of $\mathrm{C} 3$ and $\mathrm{C} 5$. Routal and Pal (1999), studying the spinal cord of 8 cadavers, concluded that the nucleus of phrenic nerve in the anterior cornus of medulla was situated between segments C3 to C5 (Figure 1).

Banneheka (2008) found more specific results. In a study with 103 Japanese cadavers, 206 sides total, the author found the most common origin of the phrenic nerve as the segments C4 and C5, corresponding to $52 \%$ of cases; the second most common origin was segment $\mathrm{C} 4$ isolated, corresponding to $43.5 \%$ of cases. Only $1.5 \%$ of the total showed its origin in segments C3, C4 and C5. Mendelson, Deconde, Lambert et al. (2011), in his study, found the phrenic nerve formed by C3, C4 and C5 in only $22 \%$ of 56 cadavers.

Variations in the course of the phrenic nerve

The isolated most described variation in the course of the phrenic nerve is its passage anterior to subclavian vein, before reaching the thorax (Figure 2 ). In the cadaveric study of Banneheka (2008), with 206 sides, this variation was found in $2.9 \%$ of cases. Prakash, Prabhu, Madhyastha et al. (2007) also related one case in which this happened and, associated to this variation, the phrenic nerve emitted a communicating branch to root $\mathrm{C} 5$ of brachial plexus.

Rao, Kumar, Shetty et al. (2007) related one case in which the phrenic nerve, passing anterior to the scalenus anterior muscle, divided in two segments and then reunited below, before reaching the thorax, making a loop over the origin of suprascapular and internal thoracic arteries.

Furthermore, Bancroft and Stephens (2007) related an isolated variation in the thoracic course of phrenic nerve in the presence of azygos lobe on lung. The phrenic nerve passed between the two layers of parietal pleura - in azygos fissure - anterior to the azygos vein, also located in the fissure.

\subsection{Accessory phrenic nerve}

In this review, we considered an accessory phrenic nerve (APN) every nerve that contributes to phrenic nerve, after it had crossed the scalenus anterior muscle (Figure 3 ). It is the most common and most described variation of the phrenic nerve in literature.

Loukas, Kinsella Junior, Louis Junior et al. (2006), in a cadaveric study with 160 sides, found APN in $61.8 \%$ of them (Table 1), with bilateral occurrence in $38.8 \%$ of the cadavers. The most frequent origin was the nerve to subclavian (60.6\%) (Table 2), and the accessory phrenic nerve joined the phrenic nerve most commonly in thorax $(67.7 \%)$. Thirty-one per cent of the APN passed anterior to subclavian vein, forming a loop with the phrenic nerve (Figure 4): some of the loops (38.4\%) involved the internal thoracic artery and others $(45.5 \%)$ also included the subclavian vein.

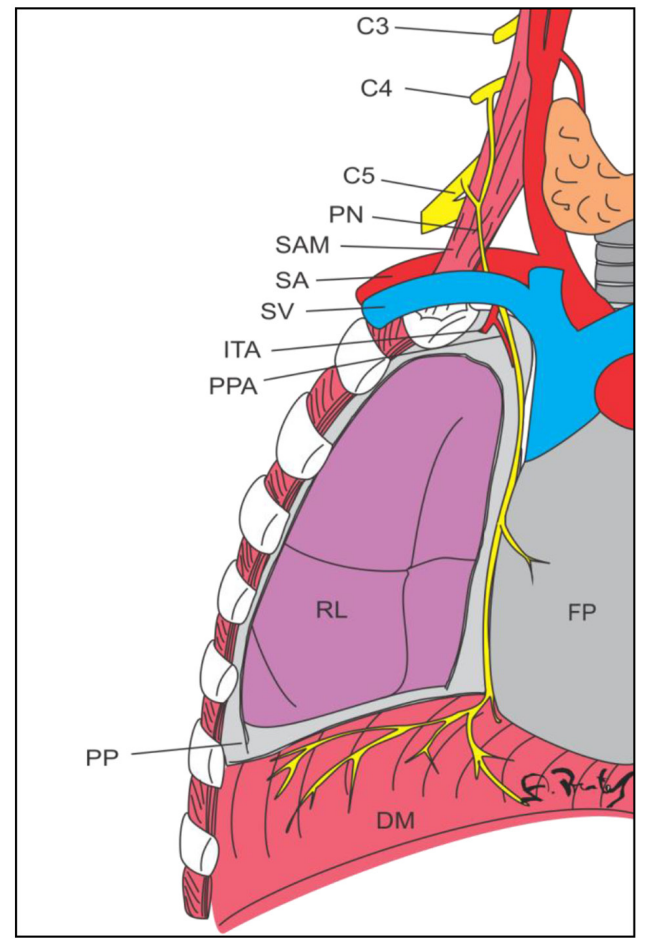

Figure 1. Course of the right phrenic nerve. C3, C4 and C5: ventral branches of medullary segments; PN: phrenic nerve; SAM: scalenus anterior muscle; SA: subclavian artery; SV: subclavian vein; ITA: internal thoracic artery; PPA: pericardiophrenic artery; RL: right lung; FP: fibrous pericardium; PP: parietal pleura; DM: diaphragm muscle.

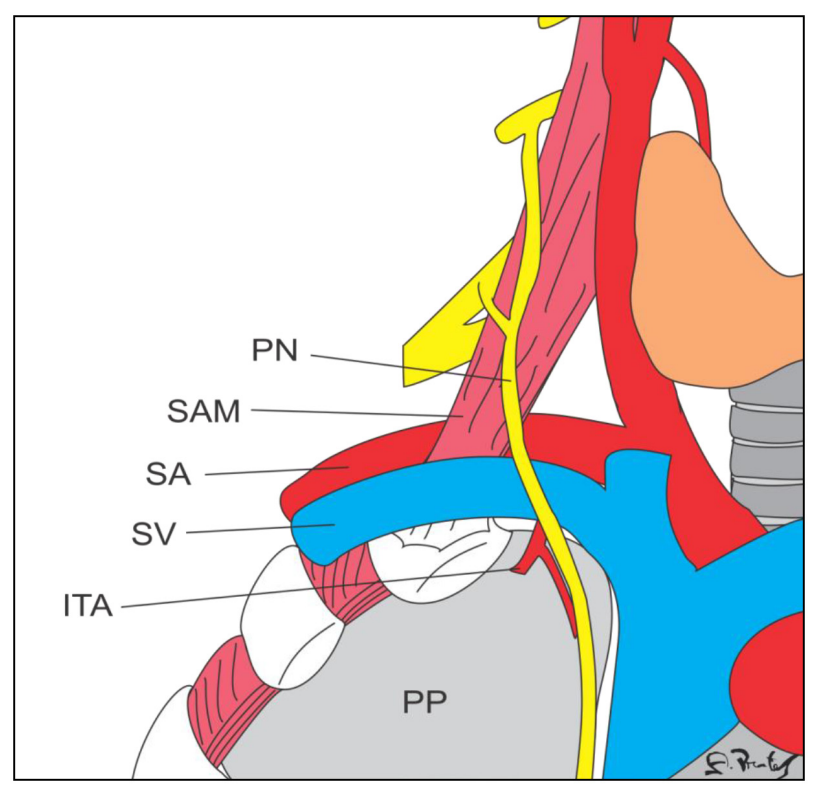

Figure 2. Phrenic nerve passing anterior to the subclavian vein. PN: phrenic nerve; SAM: scalenus anterior muscle; SA: subclavian artery; SV: subclavian vein; ITA: internal thoracic artery; PP: parietal pleura. 


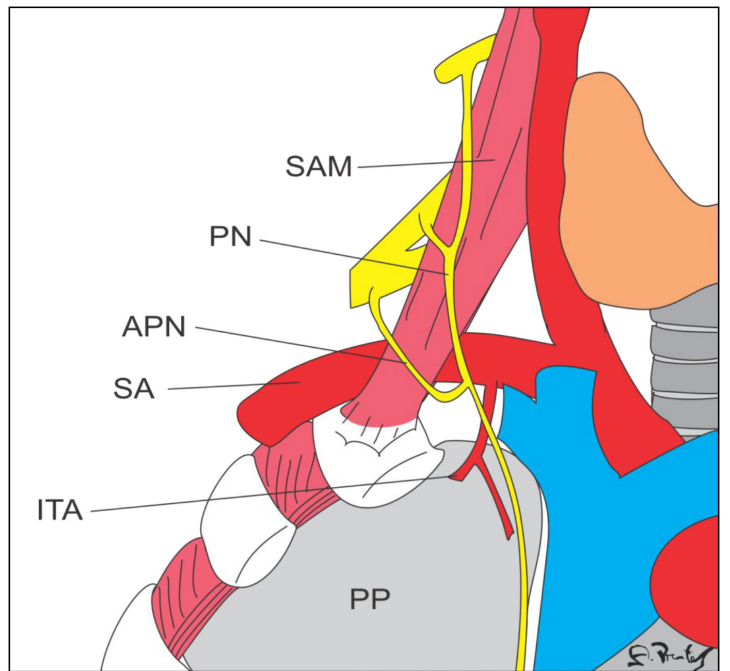

Figure 3. Accessory phrenic nerve. SAM: scalenus anterior muscle; PN: phrenic nerve; APN: accessory phrenic nerve; SA: subclavian artery; ITA: internal thoracic artery; PP: parietal pleura.

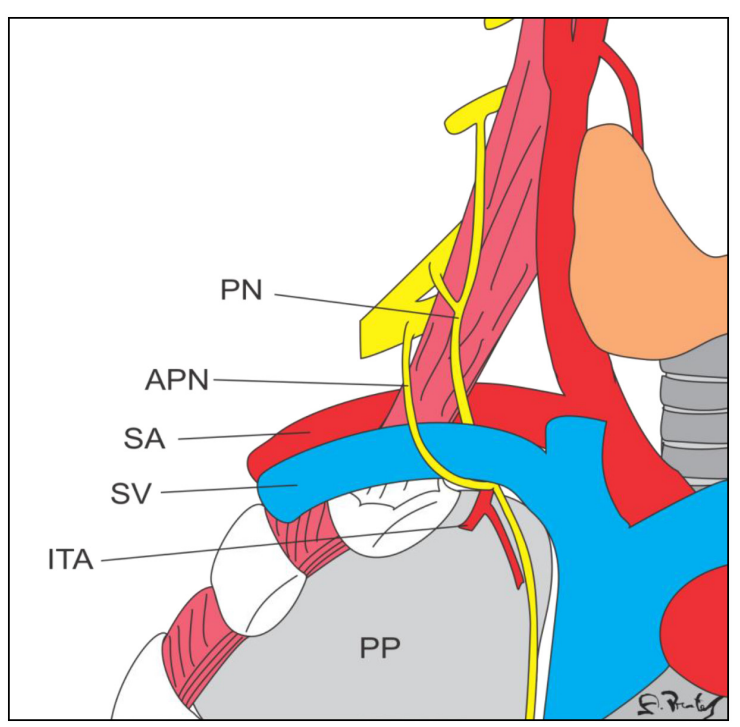

Figure 4. Accessory phrenic nerve forming a loop with the phrenic nerve and involving the subclavian vein. PN: phrenic nerve; APN: accessory phrenic nerve; SA: subclavian artery; SV: subclavian vein; ITA: internal thoracic artery; PP: parietal pleura.
Similar results were related by Nayak, Krishnamurthy, Prabhu et al. (2008) in his cadaveric study with 90 sides, in which he found APN in $53.3 \%$ of them, with bilateral occurrence in $24.4 \%$. Every time the APN reached the thorax, it passed anterior to subclavian vein and involved it in a loop formed with the phrenic nerve. The most frequent origin of APN was the nerve to subclavian $(45.8 \%)$.

Fazan, Amadeu, Caleffi et al. (2003) and Banneheka (2008) also related similar prevalence for the APN, whose most frequent origin was the nerve to subclavian. The first one, in a cadaveric study with 54 sides, described APN in $50 \%$ of them. Banneheka (2008), studying 206 sides, found it in 48\%. Other results cited by Nayak, Krishnamurthy, Prabhu et al. (2008) and Loukas, Kinsella Junior, Louis Junior et al. (2006) are listed in Table 1.

Another variation related to the APN, described by Codesido and Guerri-Guttenberg (2008), was its arise from the root of $\mathrm{C} 5$, which then passed through a ring in the subclavian vein, near of the junction with the external jugular vein, later to join the phrenic nerve in thorax.

Table 1. Frequency of accessory phrenic nerve.

\begin{tabular}{|c|c|}
\hline Author, year & $\begin{array}{l}\text { Frequency } \\
(\%)\end{array}$ \\
\hline $\begin{array}{l}\text { Nayak, Krishnamurthy, Prabhu et al. } \\
\text { (2008) }\end{array}$ & 53.3 \\
\hline Banneheka (2008) & 48 \\
\hline $\begin{array}{l}\text { Loukas, Kinsella Junior, Louis Junior et al. } \\
(2006)\end{array}$ & 61.8 \\
\hline Fazan, Amadeu and Caleffi et al. (2003) & 50 \\
\hline $\begin{array}{l}\text { Matsumura and Kumaki, 1996, cited } \\
\text { by Nayak, Krishnamurthy, Prabhu et al. } \\
(2008)\end{array}$ & 42.7 \\
\hline Bergman, Thompson, Afifi et al. (1988) & 75.7 \\
\hline $\begin{array}{l}\text { Kikuchi, 1970, cited by Nayak, } \\
\text { Krishnamurthy, Prabhu et al. (2008) }\end{array}$ & 44.2 \\
\hline $\begin{array}{l}\text { Kelley, 1950, cited by Loukas, Kinsella } \\
\text { Junior, Louis Junior et al. (2006) }\end{array}$ & 80.9 \\
\hline $\begin{array}{l}\text { Curtis, 1942, cited by Loukas, Kinsella } \\
\text { Junior, Louis Junior et al. (2006) }\end{array}$ & 24.4 \\
\hline $\begin{array}{l}\text { Aycock and Habliston, } 1930 \text {, cited by } \\
\text { Loukas, Kinsella Junior, Louis Junior et al. } \\
(2006)\end{array}$ & 65 \\
\hline
\end{tabular}

Table 2. The different origins of the accessory phrenic nerve.

\begin{tabular}{cccc}
\hline Origin & \multicolumn{3}{c}{ Authors and frequency (\%) } \\
\cline { 2 - 5 } & $\begin{array}{c}\text { Loukas, Kinsella } \\
\text { Junior, Louis } \\
\text { Junior et al. (2006) }\end{array}$ & $\begin{array}{c}\text { Nayak, } \\
\text { Krishnamurthy, } \\
\text { Prabhu et al. (2008) }\end{array}$ & Banneheka (2008) \\
\hline Nerve to the subclavian & 60.6 & 45.8 & 41.5 \\
Supraclavicular nerve & 4 & 16.6 & - \\
Ansa cervicalis & 12.1 & 16.6 & 1.8 \\
Upper trunk (C5 and C6) & - & 12.5 & - \\
C5 root & 2 & 8.3 & - \\
Sternohyoid nerve & 7.1 & - & 9.4 \\
C3 or C4 root & 8.1 & - & - \\
Accessory nerve & 4 & - & - \\
Hypoglossal nerve & 2 & &
\end{tabular}




\section{Conclusions}

The most recent studies have shown that the phrenic nerve is mainly formed by the roots of $\mathrm{C} 4$ and $\mathrm{C} 5$, with the contribution of $\mathrm{C} 3$ in only $1.5 \%$ to $22 \%$ of cases.

There are few reports in literature about the complications related to the variations of the phrenic nerve, whether on its origin, course or association with an APN. However many complications are suggested to happen due to theses variations (YANG, BAE, PARK et al., 2013; NAYAK, KRISHNAMURTHY, PRABHU et al., 2008; LOUKAS, KINSELLA JUNIOR, LOUIS JUNIOR et al., 2006).

The presence of the phrenic nerve anterior to the subclavian vein leaves it in a vulnerable position during procedures of punction and catheterism of this vessel (PARASKEVAS, RAIKOS, CHOULIARAS et al., 2011; PRAKASH, PRABHU, MADHYASTHA et al., 2007), which may be a cause of hemidiaphragmatic paralysis.

Supraclavicular anesthetic blockages are reported in literature as likely to cause a blockage on phrenic nerve and thus a hemidiaphragmatic paralysis (NEAL, MOORE, KOPACZ et al., 1998). The presence of APN could be protective in these cases, once, through it, the diaphragm muscle would also be innervated by the brachial plexus (LOUKAS, KINSELLA JUNIOR, LOUIS JUNIOR et al., 2006). On the other hand, loops between the phrenic nerve and the APN (present in $30 \%$ to $67.7 \%$ of cases with APN), during surgical manipulation, may damage some vascular structures involved by them. The studies showed (NAYAK, KRISHNAMURTHY, PRABHU et al., 2008; LOUKAS, KINSELLA JUNIOR, LOUIS JUNIOR et al., 2006) that loops frequently involve the internal thoracic artery, which makes the phrenic nerve more susceptible to be damaged during surgeries of myocardial revascularization, when using this artery (NAYAK, KRISHNAMURTHY, PRABHU et al., 2008; LOUKAS, KINSELLA JUNIOR, LOUIS JUNIOR et al., 2006). Furthermore, the APN itself when passing anterior to the subclavian vein, can be damaged during the catheterism of this vessel, leading to a hemidiaphragmatic paresis, secondary to the interruption of part of the efferent fibers that innervate one hemidiaphragm.

The APN is a very current variation, present in over $40 \%$ of the cadavers, in the majority of the studies, and physicians should always considerate its possible occurrence when performing thoracic surgeries.

When variations of the phrenic nerve are present, even procedures that are widely performed may cause damage. Considering this, the knowledge of its normal anatomy and its possible variations is indispensable, in order to ensure a safe procedure and enable early recognition of complications.

\section{References}

ANSON, BJ. and MCVAY, CB. Surgical anatomy. 5th ed. Philadelphia: W.B. Saunders Company, 1971.

BANCROFT, A. and STEPHENS, RE. Course variability of the phrenic nerve in the presence of an azygos lobe: two case reports. Clinical Anatomy, 2007, vol. 20, n. 8, p. 982-983. PMid:17109439.

BANNEHEKA, S. Morphological study of the ansa cervicalis and the phrenic nerve. Anatomical Science International, 2008, vol. 83, n. 1, p. 31-44. PMid:18402086.
BERGMAN, RA., THOMPSON, SA., AFIFI, AK. and SADDEH, FA. Copendium of human anatomical variation. Baltimore: Urban and Schwarzenburg, 1988.

CODESIDO, M. and GUERRI-GUTTENBERG, RA. Right accessory phrenic nerve passing through an annulus of the subclavian vein. Clinical Anatomy, 2008, vol. 21, n. 8, p. 779-780. PMid:18627105.

FAZAN, VPS., AMADEU, AS., CALEFFI, AL. and RODRIGUES FILHO, OA. Brachial plexus variations in its formation and main branches. Acta Cirurgica Brasileira, 2003, vol. 18, n. 5, p. 14-18.

LOUKAS, M., KINSELLA JUNIOR, CR., LOUIS JUNIOR, RG., GANDHI, S. and CURRY, B. Surgical anatomy of the accessory phrenic nerve. The Annals of Thoracic Surgery, 2006, vol. 82, n. 5, p. 1870-1875. PMid:17062263.

MACHADO, A. Neuroanatomia funcional. 2. ed. São Paulo: Atheneu, 1998.

MENDELSOHN, AH., DECONDE, A., LAMBERT, HW., DODSON, SC., DANEY, BT., STARK, ME., BERKE, GS. and WISCO, JJ. Cervical variations of the phrenic nerve. The Laryngoscope, 2011, vol. 121, n. 9, p. 1920-1923. PMid:22024845.

MOORE, KL., DALLEY, AF. and AGUR, AMR. Anatomia orientada para a clínica. 6. ed. Rio de Janeiro: Guanabara Koogan, 2011.

NAYAK, SR, KRISHNAMURTHY, A., PRABHU, LV., RAMANATHAN, L., PAI, MM., POTU, BK. and DAS, S. Incidence of accessory phrenic nerve and its clinical significance: a cadaveric study. Acta Medica, 2008, vol. 51, n. 3, p. 181-184. PMid:19271686.

NEAL, JM., MOORE, JM., KOPACZ, DJ., LIU, SS., KRAMER, DJ. and PLORDE, JJ. Quantitative analysis of respiratory, motor, and sensory function after supraclavicular block. Anesthesia and Analgesia, 1998, vol. 86, n. 6, p. 1239-1244. PMid:9620512.

PARASKEVAS, GK., RAIKOS, A., CHOULIARAS, K. and PAPAZIOGAS, B. Variable anatomical relationship of phrenic nerve and subclavian vein: clinical implication for subclavian vein catheterization. British Journal of Anaesthesia, 2011, vol. 106, n. 3, p. 348-351. PMid:21233111.

PETROIANU, A. Anatomia cirúrgica. Rio de Janeiro: Guanabara Koogan, 1999.

PRAKASH, R., PRABHU, LV., MADHYASTHA, S. and SINGH, G. A variation of the phrenic nerve: case report and review. Singapore Medical Journal, 2007, December., vol. 48, n. 12, p. 1156-1157. PMid:18043847.

RAO, TR., KUMAR, B., SHETTY, P. and RAO, SR. Variation in the course of the left phrenic nerve: a case report. Neuroanatomy, 2007 , vol. 6, p. 24-25.

ROUTAL, RV. and PAL, GP. Location of the phrenic nucleus in the human spinal cord. Journal of Anatomy, 1999, vol. 195, n. Pt 4, p. 617-621. PMid:10634699.

SKANDALAKIS, JE., COLBORN, GL., WEIDMAN, TA., FOSTER JUNIOR, RS., KINGSWORTH, AN., SKANDALAKIS, LJ., SKANDALAKIS, PN. and MIRILAS, PS. Skandalakis surgical anatomy: the embryologic and anatomic basis of modern surgery. 14th ed. Athens: Paschalidis Medical Publishers, 2004.

STANDRING, S. Gray's anatomy: the anatomical basis of clinical practice. 39th ed. Edinburgh: Elsevier Churchill Livingstone, 2004.

YANG, CW., BAE, JS., PARK, TI., LEE, JC., SOHN, JE., KANG, R. and LEE, KH. Transient right hemidiaphragmatic paralysis following subclavian venous catheterization: possible implications of anatomical variation of the phrenic nerve: a case report. Korean Journal of Anesthesiology, 2013, vol. 65, n. 6, p. 559-561. PMid:24427463.

Received March 31, 2014 Accepted July 8, 2015 